\title{
Tecnocracia y democracia en el Chile contemporáneo: el caso de los gobiernos de la Concertación (1990-2010)
}

\author{
Mireya Dávila Avendaño*
}

\begin{abstract}
Resumen
Se ha relacionado la influencia del conocimiento experto en el proceso de toma de decisiones en las democracias latinoamericanas con la tecnocracia. ¿Son los tecnócratas los nuevos decision makers de las democracias latinoamericanas? Este artículo analiza los ministros y subsecretarios de los gabinetes de los cuatro gobiernos de la Concertación en Chile a través del desarrollo de un perfil de tecnócratas y políticos con el objetivo de poder medir el fenómeno tecnocrático. Se sostiene que la influencia tecnocrática está mediada por la política, es decir, los tecnócratas no son independientes a ésta. El análisis de los datos confirma este argumento. De todos los ministros tecnócratas de los gobiernos de la Concertación, sólo uno era independiente.
\end{abstract}

Palabras clave: Tecnocracia - Concertación - gobierno.

\begin{abstract}
In Latin American democracies it has been related technocracy with the influence of expertise in decision making. Are technocrats the new decision makers in these democracies? This paper analyzes ministers and undersecretaries of the four Concertación administrations. It develops a technocratic and political profile of each of these authorities with the purpose of measuring technocratic phenomenon. It is sustained that technocratic influence is mediated by politics, in other words, technocrats are not independent from politics. The findings confirm the argument. Of all the ministers classified as technocrats, only one was independent.
\end{abstract}

Keywords: Technocracy - Concertación - government.

* PhD (c) Universidad de Carolina del Norte, Chapel Hill, Estados Unidos. Master of Arts Political Science, UNC-Chapel Hill. 


\section{INTRODUCCIÓN}

Se ha relacionado la influencia del conocimiento experto en el proceso de toma de decisiones en las democracias latinoamericanas con la tecnocracia y los tecnócratas. Esta influencia en la selección y diseño de políticas se ha visto frecuentemente como una amenaza a la democracia y la política. Esta tensión se origina en dos dimensiones: representación y calidad de las políticas. Primero, se argumenta que como los tecnócratas basan su influencia en su expertise, no cumplen con el principio de representación que es inherente a los regímenes democráticos. Por el contrario, los políticos basan su influencia en la representación de sus electores, su partido. Entonces si la tecnocracia aumenta su influencia, la democracia puede ser debilitada porque la representación disminuye. La segunda dimensión se relaciona con la calidad de las políticas. Se argumenta que las políticas son diseñadas por los tecnócratas aisladamente y que al no tener mecanismos de participación éstas serán de más mala calidad. Esto es especialmente cierto para América Latina, donde los tecnócratas han sido relacionados con el diseño de las reformas neoliberales. Pero ¿̇hasta qué punto la tecnocracia se opone a la democracia? ¿Cuál es la naturaleza de la relación entre tecnocracia y política? ¿Son los tecnócratas los nuevos decision makers de las democracias latinoamericanas? Este artículo contribuye a este debate analizando el caso chileno, específicamente los gabinetes (ministros y subsecretarios) de los gobiernos de la Concertación a partir de 1990 a través del desarrollo de un perfil de tecnócratas y políticos que permita caracterizar empíricamente el fenómeno tecnocrático en la democracia chilena postautoritaria.

Si bien se ha argumentado que en el caso chileno el origen de la influencia tecnocrática en la democracia proviene de los think tanks opositores a Pinochet (Montecinos, 1998) y del vínculo de éstos con los partidos, incluso afirmándose la creciente influencia de éstos en los gobiernos de esta coalición presidencial, no se ha desarrollado una medición empírica que permita conocer y comparar la presencia tecnocrática en los gabinetes desde 1990.

El argumento de este artículo es que la influencia tecnocrática en Chile está mediada por la política, es decir, los tecnócratas no son independientes a ésta. Es decir, sigue lo sostenido por diversos autores (Ai Camp, 1995; Domínguez, 1997) en el sentido de que los tecnócratas son también políticos. En lo que sí los tecnócratas difieren de los políticos tradicionales es en cuanto a su trayectoria política. Como veremos más adelante, la trayectoria de ambos decision makers es diferente. El análisis de los datos confirma este argumento. De todos los ministros tecnócratas de los gobiernos de la Concertación, sólo uno no tiene militancia política. Por otro lado, la presencia tecnocrática, al menos a nivel de ministros, no permite concluir que Chile sea un caso de democracia tecnocrática (como lo argumenta Centeno, 1993). Por el contrario, si algo se puede evidenciar es precisamente el balance entre el expertise técnico y político.

A continuación damos cuenta de los principales aspectos desarrollados por la literatura respecto a la tecnocracia, a partir de los cuales esperamos poder avanzar con nueva evidencia empírica. Justamente, una de las debilidades de esta literatura es la falta de precisión en la conceptualización y los escasos datos que permiten comparar y avanzar en 
el conocimiento teórico de la tecnocracia. Luego desarrollamos una tipología para definir a los tecnócratas y los políticos, con el fin de testearla para el caso de la Concertación y sus cuatro administraciones, la cual nos sirve en la sección posterior para analizar los cuatro gobiernos de la coalición y sus gabinetes.

\section{II. ¿QUÉ DICE LA TEORÍA?}

Existe acuerdo en que la tecnocracia es un fenómeno político, pues se relaciona con quién decide, quién finalmente influye en los asuntos públicos, en las políticas ${ }^{1}$. Desde su origen, se ha visto a la tecnocracia como un fenómeno político opuesto a la democracia por la naturaleza no electa de estos actores (Meynaud, 1968; Fischer, 1990; Centeno, 1993). Los esfuerzos han estado en caracterizar a estos actores y en relación con la democracia y las reformas neoliberales de las últimas décadas en América Latina.

El debate sobre la tecnocracia se originó en los sesenta especialmente en Estados Unidos $^{2}$ y Francia (Akin, 1977; Picon, 2007). De acuerdo a Meynaud (1968) el concepto fue oficialmente establecido en el área científica en 1949, pero fue acuñado en Estados Unidos después de la Primera Guerra Mundial para describir un sistema de pensamiento económico inspirado en el análisis racional basado en las ciencias físicas. La base fundamental de la tecnocracia es su fe en la eficiencia.

\subsection{Caracterizando a los tecnócratas}

Como señalamos, una de las primeras características de esta literatura es que el concepto de tecnocracia es polisémico, como ocurre con muchos otros términos de las ciencias sociales, siendo usual encontrar el uso del concepto sin que éste haya sido previamente definido (Centeno, 1998; Silva, 1991). Como dijimos, el concepto de tecnócrata se relaciona con la necesidad de distinguir este decision maker de los políticos tradicionales. Algunos autores se centran en definir las trayectorias de los tecnócratas (Ai Camp, 1985), otros las características de sus decisiones (Fischer, 1990) y otros los relacionan con ideologías en particular (Teichman, 2001).

Una primera distinción entre tecnócratas y políticos tradicionales se basa en la naturaleza de su influencia. Diversos autores coinciden en que una primera diferencia de los tecnócratas es que ellos basan su influencia en su expertise, mientras que los políticos lo hacen en su experiencia en las elecciones competitivas (Fischer, 1990; Centeno y Silva, 1998). Collier (1979) añade que este alto nivel de entrenamiento académico especializado sirve como criterio de selección para ocupar cargos en la cúspide del proceso de toma de decisiones o como asesores en organizaciones complejas tanto públicas como privadas.

1 Una posición distinta es argumentada por Grindle (1977), quien sostiene que la tecnocracia es un actor independiente de la política.

2 Para el caso de Estados Unidos, Akin (1977) sostiene que en los 30 la tecnocracia era anticapitalista y antidemocrática. 
Una segunda se relaciona con el nivel de influencia de estos actores. La literatura diferencia a los tecnócratas de los técnicos por el nivel de influencia de los primeros en el proceso de toma de decisiones (Meynaud, 1968). Los técnicos son expertos bajo la dirección de otras élites, mientras que los tecnócratas son actores que tienen acceso a decisiones que van más allá de su área de expertise y que generalmente han sido monopolio de los políticos.

Algunos autores han incluso argumentado la existencia de Estados tecnocráticos, los cuales se caracterizan por la gran influencia de éstos en las decisiones públicas (Centeno, 1993). Estos Estados presentan tres características que los definen: la penetración de élites tecnocráticas en los niveles altos de la administración; la influencia predominante de las instituciones dominadas por tecnócratas, y las políticas en un Estado de este tipo tienen un marcado acento tecnocrático. En estas democracias los representantes elegidos por la gente tienen sólo un control nominal, pues el diseño de las políticas está en manos de los tecnócratas. La mayoría de la gente no entiende las políticas y los políticos tienen que saber de economía. Centeno (1993) ejemplifica con Chile este tipo de Estado³. Más allá de que este artículo pueda contraargumentar sólo centrándose en la cantidad de tecnócratas presentes en el nivel superior de gobierno, creemos que el Estado chileno dista de ser uno tecnocrático como lo han definido algunos autores. En nuestra opinión la naturaleza del sistema político chileno y su influencia en el Estado hacen difícil todavía poder hablar de Chile como un Estado tecnocrático. Sin duda este es un punto sobre el cual es necesario desarrollar una mayor discusión.

Ahora, en términos concretos, es difícil poder establecer claramente qué tipos de políticas favorecerían o no a los tecnócratas. En otras palabras, ¿cuánto de tecnocrática o política tiene una política pública? Esto es muy difícil de poder cuantificar y, por ende, de establecer categorizaciones, por lo que la literatura se centra más bien en caracterizar a estos actores (por ejemplo en base a su educación, como es el caso de Ai Camp para México, 1985). Otra alternativa es ejemplificar el perfil e influencia de los tecnócratas a través de la caracterización de ciertos tecnócratas en especial ${ }^{4}$.

Una tercera forma de poder caracterizar a estos decision makers es distinguiendo su trayectoria académica, lo que los diferencia, en general de los políticos tradicionales (Ai Camp, 1985, 1995; Domínguez, 1997)5. Ai Camp (1985) sostiene que si bien todos los top decision makers son políticos, se pueden distinguir ciertos tipos de políticos en base a su educación, carrera, patrones de reclutamiento y fuente de influencia. Para el caso mexicano este autor analiza los gabinetes de ministros y subsecretarios entre 1935 y 1983 y nota que si bien la mayoría son abogados, ha habido un aumento de economistas, ingenieros y arquitectos. Para Ai Camp (1995) la mejor definición de tecnocracia se relaciona con la

También Taiwán, Corea del Sur, Singapur y México.

Como es el caso de Domingo Cavallo en Argentina (Corrales, 1997), Evelyn Matthei (Boylan, 1997) y Pablo Ramírez en Chile (Silva, 1998).

5 Veremos más adelante que para el caso chileno también se puede observar una tendencia a tener una trayectoria política más débil, pues la mayoría son sólo militantes. 
educación de doctorado. Este autor define a los tecnócratas-políticos mexicanos como líderes que tienen entrenamiento en economía y tienen estudios fuera del país ${ }^{6}$, conocimiento del modelo norteamericano, una carrera nacional ejecutiva y experiencia profesional relacionada con agencias económicas ${ }^{7}$. La explicación para que estos actores capturen la cúspide del poder dentro del Estado es la habilidad para capturar los puestos más altos de la burocracia económica. Este difiere del político tradicional de los sesenta y setenta por la falta de experiencia política, que nunca haya sido elegido para cargos de representación popular y por tener una educación fuera del país. Este autor señala que los tecnócratas no son un fenómeno nuevo en la política mexicana, lo nuevo es que dominan los niveles superiores, incluso la presidencia. Esto se relaciona con un cambio de valores donde el expertise es visto como un activo para mantener la estabilidad del sistema político (Ai Camp, 1983) ${ }^{8}$. En el caso mexicano es mejor hablar de tecnócratas políticos en vez de tecnócratas a secas $(1985,1993)^{9}$.

Por otro lado, también se caracteriza a los tecnócratas como funcionarios de alto rango que no poseen experiencia electoral (Ross Schneider, 1998). Esto implica que en la toma de decisiones los políticos basan su criterio en la reelección, mientras que los tecnócratas en el criterio técnico. Ross Schneider (1998) destaca cuatro mecanismos causales para el ascenso de los tecnócratas: 1) la modernización; 2) el pluralismo (tecnócratas como redes); 3) la delegación (los políticos delegan el poder para controlar la incertidumbre), y 4) la confianza de los inversores. Para este autor la crisis económica le dio poder a los tecnócratas neoliberales.

En cuanto a la profesión de los tecnócratas, algunos son más precisos que otros en definir las profesiones. Hay quienes argumentan que los tecnócratas provienen de las ciencias sociales duras como negocios, administración y leyes (Ross Schneider, 1998), otros los vinculan especialmente con la profesión de economistas (Ai Camp, 1983; Montecinos, 1993; Whitehead, 1997). Silva (2009) argumenta que si bien la mayoría de los tecnócratas son ingenieros, economistas, expertos financieros o administradores, personas con educación formal en sociología y ciencia política pueden ser tecnocratizados y aceptar que las decisiones pueden ser tomadas por expertos.

6 Universidades como Yale, Harvard, Stanford, Pennsylvania e Iberoamericana en Estados Unidos e ITAM y UNAM en México.

7 En México hay tres instituciones económicas importantes: Secretaría del Tesoro, Programación y Presupuesto y Banco de México.

$8 \quad$ El análisis del rol cada vez más influyente de los tecnócratas en las políticas de privatizaciones del sistema de pensiones en México llevadas a cabo en las décadas de los 80 y 90 confirman lo argumentado por Ai Camp (1995) en cuanto a la caracterización de éstos como profesionales con una carrera académica con formación de postgrado en universidades norteamericanas, generalmente en economía o administración, por lo que también impulsaron reformas basadas en el supuesto de la mayor eficacia del mercado, por sobre el Estado, en la asignación de los bienes públicos. Por su parte, los expertos tenían muy poca experiencia en política partidaria. Sin embargo, su poder de influencia no ha sido homogéneo dentro de todo el Estado, ya que generalmente han estado concentrados en los ministerios de Finanzas, Hacienda, Planificación y el Banco Central (Madrid, 2004).

9 Como veremos más adelante, Domínguez (1997) define esta versión híbrida como technopols. 
Montecinos (1997) relaciona la introducción de reformas estructurales con la influencia tecnocrática y la creciente influencia de los economistas. Uno de los factores que la autora piensa que incide en esta tendencia es la ausencia de paradigmas económicos diferentes, cosa que sí observaba anteriormente. Una perspectiva diferente sostiene que la delegación de poder de la autoridad política a los expertos no está relacionada con el neoliberalismo, ni es un fenómeno nuevo en América Latina. Lo que sí es nuevo a partir de la crisis de los ochenta es el tipo de experto. Antes eran intelectuales o generalistas; en cambio, ahora están inspirados en la economía y son economistas profesionales (Whitehead, 1997).

Finalmente es necesario destacar que para el caso de América Latina diversos autores (Ai Camp, 1985; Domínguez, 1997) argumentan que el tecnócrata puro no existe, sino más bien los políticos tecnócratas como los llama Domínguez.

\subsection{Tecnocracia, democracia y reformas económicas}

Otro aspecto en el debate sobre la tecnocracia en América Latina la relaciona con el tipo de régimen (democracia o dictadura) (Lindau, 1996) y a una cierta ideología, en este caso, el neoliberalismo.

Se argumenta que existe una cierta afinidad entre la tecnocracia y el capitalismo porque enfatizan la eficiencia (Centeno, 1993). Asimismo, se ha vinculado a los tecnócratas con la introducción de reformas neoliberales en la región, especialmente las versiones más ortodoxas (Ross Schneider, 1998; Domínguez, 1997; Silva, Teichman, 2001; Huneeus, 1998a; Silva, 2008).

Para algunos autores el incremento en la importancia de la élite tecnocrática en la toma de decisiones sobre política es vista como un factor determinante en la implementación de las reformas estructurales (Haggard y Webb, 1994; Haggard y Kauffman, 1995; Pastor y Wise, 1992; Teichman, 1997; Teichman, 2001).

Por ejemplo, Domínguez (1997) propone el concepto technopol para definir un decision maker particular que combina el expertise técnico y la capacidad política y que está vinculado con la implementación de las reformas neoliberales en América Latina. Él define a los technopols como figuras públicas con un alto entrenamiento técnico y figuración política que han hecho de la economía algo político y que han establecido alianzas políticas para gobernar más efectivamente. Estos technopols han hecho las políticas económicas aceptables para el público en general tanto en contextos democráticos como autoritarios. Para el autor no existe relación entre los technopols y el régimen político, pues ellos ofrecen una metodología para comprender los problemas sociales que descansa en la habilidad para llegar a una solución óptima para cualquier problema. Los criterios claves para la acción son el realismo y la eficiencia. Estos technopols son una variante de los tecnócratas, pues son tecnócratas, pero también son líderes políticos.

Centeno (1998) se pregunta el por qué de este vínculo entre tecnócratas y neoliberalismo, lo que es respondido analizando el trabajo de Hayek como un ejemplo de uno de los 
pensamientos tecnocráticos más constantes en la región: la fe en el mercado y el consumidor y la desconfianza de la democracia y la elección de los votantes. Centeno señala que esto se prueba por la relación ambivalente que tiene la tecnocracia con la democracia, al buscar proteger a la población de sus peores instintos políticos y al mismo tiempo confiando en que son capaces de tomar buenas decisiones económicas.

Contrariamente al caso chileno y mexicano, los estudios señalan que en Perú los tecnócratas han tenido menos influencia, y por lo tanto son menos distinguibles como un actor político. Ello, en gran medida porque, a diferencia de Chile, en este país este grupo no ha sido ideológicamente homogéneo (Conaghan, 1998). Por su parte, en Argentina la influencia de este actor tampoco ha sido constante en las últimas décadas. Así, durante el período de Menem este grupo tuvo una gran influencia en relación al gobierno anterior, dado que en el último período ellos contaron con más respaldo político (Huneeus, 1998). Es así que para algunos autores la influencia de los tecnócratas en las reformas está intermediada por la política (Huneeus, 1998).

La relación entre tecnocracia y autoritarismo es evidenciada por Mauceri (1997) para el caso de Fujimori en Perú. Mauceri (1997) sostiene que Fujimori gobernó con dos grupos: tecnócratas y una red informal de personas leales. El autor destaca el rol de los tecnócratas en la reforma del Estado y las privatizaciones; además tuvieron un papel destacado en vincular al gobierno con los IFI y el sector privado local.

Por otro lado, la relación entre tecnocracia y reformas neoliberales o estructurales pasa por, según algunos autores, el grado de autonomía de la política que han tenido los tecnócratas (Silva, 1997; Loureiro, 1997; Montecinos, 1997; Centeno, 1997; Ross Schneider, 1997; Corrales, 2003), lo cual se explica a su vez por el debilitamiento de los partidos políticos, especialmente los de izquierda, de las organizaciones sindicales y del movimiento estudiantil. En este sentido, se argumenta que las dictaduras asestaron un golpe al populismo, pues los líderes se dieron cuenta que el desborde de ofertas y demandas sociales podía derivar en una situación inmanejable que derrumbaría nuevamente la democracia. Algunos autores añaden que en América Latina la toma de decisiones fue aislada de los controles democráticos y que este estilo tecnocrático no cambió con la llegada de la democracia (Loureiro, 1997; Teichman, 2001). Asimismo, un tercer argumento que relaciona a los tecnócratas con las reformas es que la mayor visibilidad dada a éstos se relaciona con la necesidad de dar señales al mundo de los negocios y las finanzas de que el manejo económico está bien. Se han convertido en la contraparte nacional a expertos financieros internacionales (Ross Schneider, 1997).

Un ejemplo de la autonomía de los tecnócratas para diseñar las reformas económicas de las últimas décadas es señalada por Corrales (2003) para el caso venezolano. Este autor argumenta que para enfrentar la falta de credibilidad de la ciudadanía frente a las reformas, los tecnócratas, especialmente en los equipos económicos, obtuvieron autonomía del Presidente para operar planes de reforma que incluso implicó cambios institucionales. 


\subsection{La tecnocracia en Chile}

Para el caso chileno la literatura se ha centrado especialmente en el rol de garantes en la administración de recursos y de mediadores entre la política y diferentes grupos que han tenido los tecnócratas (Silva, 1996, 2009), en la influencia de éstos durante la dictadura y posteriormente en los gobiernos democráticos (Montecinos, 1998; Hunneus, 2001), así como en su vinculación con la economía.

Silva $(1994,1996,2009)$ muestra que la importancia de los tecnócratas en el Estado data de los años 20, aunque ya destaca una cierta racionalidad tecnocrática en algunos intelectuales decimonónicos ${ }^{10}$. Ya desde esa época ellos han ocupado posiciones estratégicas como mediadores entre actores sociales y políticos, que muchas veces articulaban lógicas contrapuestas. En esta mediación, los tecnócratas proveían garantías mínimas de la correcta administración de los recursos. Esto les otorgó siempre un gran grado de autonomía, pudiendo mantenerse ajenos a los conflictos entre partidos (Silva, 1996). Ello, a diferencia de México, en cuyo caso la importancia de los tecnócratas se da en un contexto de despolitización y pérdida de fuerza de los actores políticos (Silva, 1996).

Los estudios han mostrado que los tecnócratas jugaron un rol central en la introducción de las reformas neoliberales (Huneeus, 1998, 2001; Teichman, 2001). Si bien los tecnócratas durante la dictadura no participaban directamente de la política partidaria, sí pertenecían a redes sociales y políticas de un sector de la derecha chilena, el gremialismo (Hunneus, 2001). Como han mostrado diversos estudios, la homogeneidad ideológica de este grupo se origina en su común formación académica de postgrado en la Universidad de Chicago, por lo que han sido comúnmente llamados Chicago Boys ${ }^{11}$ (Hunneus, 2001). Los tecnócratas trabajaban preferentemente en los ministerios de Hacienda, Economía y en ODEPLAN ${ }^{12}$. Estos tenían un alto grado de influencia y cohesión. La mayoría eran economistas o ingenieros y eran personas políticamente de derecha que compartían los objetivos de los militares. Huneeus (1998) argumenta que los Chicago Boys y los gremialistas no eran dos grupos separados sino uno solo, y que la coherencia provenía de la política y no de la economía. Los gremialistas tenían un proyecto estratégico que era crear una democracia protegida con una economía de mercado y los Chicago Boys estaban encargados de las reformas orientadas a la liberalización de la economía.

10 Silva (1998) analiza el rol de los tecnócratas en oposición a los resabios del orden oligárquico. Bajo la dirección del ministro de Hacienda, Pablo Ramírez, que instaló ingenieros en la administración. Después al ser creada la CORFO, la labor de los tecnócratas fue validada. Por otro lado, Rehren (1998) argumenta que Alessandri incorporó técnicos independientes en su gabinete, quienes serán sus colaboradores más directos y actuarán a través del Ministerio del Interior. Debido a su composición tecnocrática, se le denominó "gabinete de gerentes".

11 El origen de éstos estuvo en los estudios y en las redes creadas por quienes viajaron a Estados Unidos a estudiar postgrados en la Universidad de Chicago. Entre 1955 y 1963, 30 economistas de la Universidad Católica viajaron a Chicago donde aprendieron el conjunto de políticas neoliberales (Silva, 1991).

12 Oficina de Planificación Nacional. 
Por otro lado, se argumenta que entre 1974 y 1978 Pinochet personalizó el poder y generó vínculos con los Chicago Boys, que no sólo eran tecnócratas neoliberales sino también tenían vínculos con poderosos conglomerados económicos internacionales (Silva, E., 1993).

Se ha sugerido que la influencia que tuvieron los tecnócratas una vez terminado el régimen autoritario se originaría en el rol que jugaron los expertos economistas en el proceso de renovación ideológica sufrido por los partidos de izquierda que se oponían a la dictadura. Así, como propone Montecinos (1998), este actor habría empezado a ganar terreno dentro de la política partidaria. Además, los planteamientos políticos basados en argumentos económicos se desarrollaban en diversos centros de estudios independientes que surgieron en aquella época, ligados a los partidos de centro y de centro-izquierda. En ellos, se desarrollaron importantes lineamientos sobre las políticas públicas, las que serían posteriormente aplicadas durante el primer gobierno democrático (Montecinos, 1998). Por su parte, muchas de las personas que luego ocuparían cargos clave en el diseño de políticas públicas en democracia se habrían nutrido de las nuevas corrientes teóricas aprendidas durante sus estudios de postgrado, estando en el exilio. La autora sugiere que este grupo habría provisto la contraparte tecnocrática de centro-izquierda a los Chicago Boys, quienes tenían una clara orientación de derecha (Montecinos, 1998).

El factor que se menciona para lo que se denomina una "oposición tecnocrática a Pinochet" se basa entonces en estos estudios de postgrado en el exilio que tuvieron que hacer los políticos (Silva, 2006). Por ejemplo, señala Silva, en el caso de Aylwin, su gobierno tuvo un carácter altamente tecnocrático. Según este autor este carácter tecnocrático fue estimulado por tres factores: este gobierno de coalición necesitaba un modus operandi que garantizara el abandono de las cuotas (se criticaba a Allende la distribución de cargos basados en criterios políticos y no técnicos). El gobierno aceptó el criterio de la tecnocracia neoliberal de que era el expertise técnico y no político el criterio de selección. El factor es el up-grade académico de los políticos en el exilio y, finalmente, la necesidad de estabilidad económica. El equipo económico de Aylwin estuvo formado por personas con estudios de posgrado en el extranjero y vinculados a think tanks ${ }^{13}$.

Los estudios proponen (aunque sin mostrar evidencia empírica) que la credibilidad otorgada por sus credenciales profesionales les dio a este grupo la base de legitimidad necesaria para transformarse en un actor clave durante los años de la transición (Montecinos, 1998; Silva, 1995) y democracia (Moreno, 2007). De esta manera, durante los primeros años de democracia los tecnócratas no habrían dejado de tener poder dentro del Estado,

13 Ministro de Hacienda Alejandro Foxley (Universidad de Wisconsin), Subsecretario Pablo Piñera (Universidad de Boston), Jefe de Gabinete Andrés Velasco (Universidad de Columbia), Director de Presupuesto José Pablo Arellano (Universidad de Harvard), Director de Impuestos Internos Javier Etcheberry (Universidad de Michigan), Coordinador de Política Manuel Marfán (Universidad de Yale), Ministro de Economía Carlos Ominami (Universidad de París), Subsecretario de Economía Jorge Marshall (Universidad de Harvard), Coordinador de Políticas Sectoriales Alejandro Jadresic (Universidad de Harvard), Servicio Nacional de Pesca (Universidad de Wales), Secretario de Inversiones Extranjeras Fernán Ibáñez (MIT). 
sino, al contrario, los economistas habrían visto reforzada su influencia en el proceso de políticas públicas y también dentro de los partidos políticos (Montecinos, 1998, 2003). Como sugiere esta autora, durante el gobierno de Aylwin se creó dentro del Estado una red transversal a los partidos políticos de la Concertación de personal técnico que daba sustento a políticas coherentes y estables (Montecinos, 1998). Además, esta red habría tenido una gran autonomía ideológica de los partidos políticos. El poder de influencia de esta red de profesionales se potenciaba con el hecho de que tanto Aylwin como Frei habrían privilegiado las habilidades técnicas a la hora de nombrar a sus colaboradores cercanos, en detrimento de los partidos tradicionales y sus estructuras partidarias (Silva, 1996). La continuidad de esta estrategia de gobierno se explicaría en parte por los buenos resultados económicos de la época, los que le dieron un sustento de legitimidad a este sector del Estado (Montecinos, 1994).

Para el caso chileno también se relaciona a los tecnócratas con una profesión en especial, la de economista. Se argumenta que el rol de los economistas en el proceso de toma de decisiones ha aumentado desde que el primer economista ocupó la Dirección de Presupuesto durante el gobierno de Alessandri (Markoff y Montecinos, 1993). Se añade además que los economistas no sólo han penetrado el Estado sino también los partidos políticos. Los economistas dieron a los partidos de oposición a la dictadura un nuevo discurso. Como señala Montecinos (1997), el despliegue de economistas indicó la conformidad de los partidos con algunos de los rituales nuevos, que presuntamente garantizaban tanto la legitimidad política como el interés por la eficiencia, la estabilidad macroeconómica y la competitividad internacional.

Además se argumenta que existe relación entre la presencia tecnocrática y la necesidad de disminuir la inestabilidad política, como los períodos entre 1931 y 1938 y entre 1988 y 1990 (Silva, 2006).

En el trabajo más reciente sobre tecnocracia para el caso chileno, Silva (2009) afirma que la democracia puede coexistir con la tecnocracia, como es el caso de la Concertación. La presencia de la tecnocracia en el caso de la Concertación se debe a la necesidad de mantener el modelo económico y por el proceso de aprendizaje político vivido por la élite. El autor se enfoca en los equipos económicos de los cuatro gobiernos de la Concertación, aun sin comparar exactamente los mismos cargos y perfiles. Para el caso de Aylwin se incluyen 21 tecnócratas, 19 para Frei. Para los gobiernos de Lagos y Bachelet no se incluye el detalle de aquellos decision makers considerados como tecnócratas. Como señalamos, para Silva los tecnócratas pueden ser economistas, ingenieros, abogados y también sociólogos y cientistas políticos que se hayan "tecnocratizado".

Como se desprende de lo mencionado anteriormente, resulta muy necesario entonces poder determinar la presencia de tecnócratas en los gabinetes de la Concertación como un primer paso para analizar la influencia de éstos en las políticas y gestión del gobierno, por un lado, y en la aplicación del modelo de desarrollo económico, por otro. 


\section{HACIA UNA TIPOLOGÍA DE TECNÓCRATAS Y POLÍTICOS}

En esta sección desarrollamos una tipología de tecnócratas y políticos con el objetivo de poder dimensionar empíricamente el fenómeno tecnocrático en los gobiernos de la Concertación entre 1990 y 2010 (marzo) para así contribuir a conocer la naturaleza de la relación entre democracia y tecnocracia. Como señalamos anteriormente es difícil poder medir cuán tecnocrática o no es una política, por lo que para poder conocer la naturaleza del fenómeno tecnocrático en la democracia chilena contemporánea partiremos analizando los gabinetes de los cuatro gobiernos de la Concertación, a partir de los perfiles de los ministros y subsecretarios.

Definiremos tecnócratas como aquellos decision makers en los niveles superiores de la administración de un gobierno (para este caso analizaremos los ministros y subsecretarios) con un alto nivel de educación formal (doctorado en economía) y sin experiencia política (sin militancia). En este sentido, estamos relacionando a los tecnócratas mayoritariamente con la economía, tanto a nivel de pregrado como de postgrado (ver Cuadro 1). A partir de esta definición construimos una escala o perfil tecnocrático que parte del 0 y termina en el 5, que es el doctorado en economía.

Además, para poder determinar la relación existente entre tecnócratas y políticos en el caso chileno, construimos también una escala o perfil del político, partiendo de 0 , que es sin militancia, a 4, que es un político que tiene trayectoria política definida por haber tenido cargos de elección popular y haber tenido cargos de dirigencia en el partido (ver Cuadro 2) ${ }^{14}$.

\section{CUADRO 1}

Perfil tecnocrático

\begin{tabular}{|c|l|}
\hline CATEGORÍA & \multicolumn{1}{c|}{ TIPO DE EDUCACIÓN } \\
\hline 1 & $\begin{array}{l}\text { Sin educación formal, educación secundaria, educación de pregrado } \\
\text { incompleta }\end{array}$ \\
\hline 2 & $\begin{array}{l}\text { Educación de pregrado completa, Máster @ y Máster en Ciencias Sociales } \\
\text { y otras (exceptuando economía) }\end{array}$ \\
\hline 3 & $\begin{array}{l}\text { Educación de pregrado en Economía completa, Máster @ y Máster en } \\
\text { Economía }\end{array}$ \\
\hline 4 & PhD @ o PhD en Ciencias Sociales y otras (excepto economía) \\
\hline 5 & PhD @ o PhD en Economía \\
\hline
\end{tabular}

Fuente: elaboración propia.

14 Para esta investigación fueron definidos cargos de dirigencia política como: presidente, vicepresidente, secretario general (o cargo similar). 
CUADRO 2

Perfil político

\begin{tabular}{|c|l|}
\hline CATEGORÍA & \multicolumn{1}{|c|}{ TIPO DE CARRERA POLÍTICA } \\
\hline 0 & Sin militancia \\
\hline 1 & Militancia \\
\hline 2 & Candidato a cargos de elección popular (ganador o perdedor) \\
\hline 3 & Dirigente de partido (presidente, vicepresidente, secretario general) \\
\hline 4 & Candidato a cargo de elección popular y dirigente de partido \\
\hline
\end{tabular}

Fuente: elaboración propia.

A partir de ambos perfiles asignaremos para cada miembro de los gabinetes (ministros y subsecretarios) de las administraciones de Aylwin, Frei, Lagos y Bachelet un determinado perfil político-tecnocrático. Es así que nuestra base de datos contendrá dos categorías para cada ministro de los 4 gobiernos de la Concertación, una política y una tecnocrática ${ }^{15}$.

Afirmaremos que los perfiles puros son difíciles de encontrar, es decir, existen pocos tecnócratas independientes de los partidos, siendo la mayoría de ellos militantes. La mayoría de los tecnócratas tienen poca experiencia política, pero sí tienen un vínculo que es la militancia. Además, afirmaremos que el fenómeno tecnocrático, medido en términos de presencia de éstos en los altos cargos de gobierno, es menor del generalmente señalado para el caso chileno, por lo que para poder dimensionar la naturaleza tecnocrática de la democracia chilena postdictadura es necesario desarrollar nuevos estudios que permitan ampliar el universo estudiado a otros cargos y, al mismo tiempo, pensar en otras metodologías para poder dimensionar la influencia de los tecnócratas en las políticas públicas.

\section{LOS TECNÓCRATAS DE LA CONCERTACIÓN}

Siguiendo entonces nuestra tipología recién descrita en la sección anterior, presentamos los resultados de nuestra investigación para los cuatro gobiernos de la Concertación. Primero mostramos separadamente ministros y subsecretarios y en un tercer cuadro, la presencia de diferentes niveles de tecnocracia y política para todos los gabinetes de la Concertación ${ }^{16}$.

15 Estamos analizando el perfil y la presencia de los tecnócratas, por lo que se puede repetir más de una vez una persona.

16 Definimos cambio de gabinete cuando cambia alguno de los ministros políticos (Interior, SEGEGOB o SEGPRES) o al menos dos ministros de cualquier otro ministerio. 
Esta última medición permite "tomar una fotografía" al gobierno y así poder, a partir de esto, analizar cómo funciona la interrelación entre políticos y tecnócratas.

TABLA 1

Distribución de políticos y tecnócratas, 1990-2010 (ministros)

\begin{tabular}{|c|c|c|c|c|c|c|}
\hline $\begin{array}{c}\text { POLÍTICO (\%)/ } \\
\text { TECNÓCRATA (\%) }\end{array}$ & 1 & 2 & 3 & 4 & 5 & $\mathrm{~N}=$ \\
\hline 0 & 0 & 3 & 1,2 & 1,2 & 0,6 & 10 \\
\hline 1 & 0,6 & 25,7 & 12,8 & 4,9 & 12,2 & 92 \\
\hline 2 & 0 & 9,8 & 1,2 & 1,8 & 0 & 21 \\
\hline 3 & 0,6 & 3 & 2,4 & 3 & 0,6 & 16 \\
\hline 4 & 0 & 7,9 & 1,8 & 0,6 & 4,2 & 24 \\
\hline $\mathrm{N}=$ & 2 & 81 & 32 & 19 & 29 & 163 \\
\hline
\end{tabular}

Fuente: elaboración propia.

Como se observa en la Tabla 1 se confirma lo argumentado por los autores para América Latina (Ai Camp, 1983, 1995; Domínguez, 1997) también para el caso chileno, en cuanto a que los tecnócratas puros prácticamente son inexistentes. Como se observa, menos de un quinto de los ministros se puede calificar, según nuestro indicador, como tecnócrata $(6,1 \%)$. Ahora, prácticamente la totalidad (96\%) de aquellos ministros en la categoría 5, que es valor máximo para la escala tecnocrática, tienen algún vínculo con la política ${ }^{17}$. Ahora, de éstos, casi el 70\% (68,9\%) es sólo militante. Esto confirma lo argumentado por algunos autores respecto a la menor trayectoria política de estos decision makers en comparación con políticos más tradicionales (Ai Camp, 1995).

Por otro lado, de la Tabla 1 también se observa otro tipo de perfil de ministro en esta coalición de gobierno, el cual combina ambos expertise, el técnico y el político, pues no sólo tienen un vínculo con la política sino una trayectoria que ha implicado el generar experiencia en elecciones y en la directiva de sus partidos. Sucede también, como en el caso

17 La manera de contabilizar es perfiles de actores por gobierno, los cuales después fueron sumados. Es así que en un mismo gobierno se cuenta sólo una vez a cada ministro con determinado perfil político-tecnocrático. Pero al hacer el cuadro para toda la Concertación, sí se pueden repetir las personas. Por ejemplo, Foxley está contado como tecnócrata-político en Aylwin y después durante el gobierno de Bachelet. En su caso particular, cambió de perfil, pues aumentó su experiencia política, al ser presidente del PDC y senador. 
del ex Ministro de Hacienda de Aylwin y de Relaciones Exteriores de Bachelet, Alejandro Foxley, que ha incrementado su trayectoria política después de ser ministro de Hacienda entre 1990 y 1994. Foxley fue senador y presidente de su partido, el Demócrata Cristiano, con posterioridad a su rol como ministro. Se podría pensar entonces en especular que existen diferentes tipos de tecnócratas, y que en el caso del Ministro Foxley, su capacidad de influencia como tecnócrata le dio mayor influencia política.

Ahora, la presencia tecnocrática en el nivel inmediatamente inferior al de ministros, el de subsecretarios, es menor a la encontrada en el nivel de ministros.

TABLA 2

Distribución de políticos y tecnócratas, 1990-2010 (subsecretarios)

\begin{tabular}{|c|c|c|c|c|c|c|}
\hline $\begin{array}{c}\text { POLÍTICO (\%) } \\
\text { TTECNÓCRATA (\%) }\end{array}$ & 1 & 2 & 3 & 4 & 5 & $\mathrm{~N}=$ \\
\hline 0 & 0,4 & 3,2 & 0,4 & 0 & 0,9 & 11 \\
\hline 1 & 2,7 & 51,1 & 19 & 4,6 & 2,7 & 173 \\
\hline 2 & 0 & 5,5 & 0,4 & 2,3 & 0 & 18 \\
\hline 3 & 0,9 & 0,4 & 1,3 & 0,4 & 0,9 & 9 \\
\hline 4 & 0 & 0,9 & 0 & 0,4 & 0,4 & 4 \\
\hline $\mathrm{N}=$ & 9 & 132 & 46 & 17 & 11 & 215 \\
\hline
\end{tabular}

Fuente: elaboración propia.

Como vemos en la Tabla 2, la cantidad de tecnócratas disminuye a más de la mitad en el caso de los subsecretarios (11 en total para todos los gobiernos de la Concertación). Los tecnócratas representan el 5,1\% del total de subsecretarios para el periodo 1990-2009. Al igual que en el caso de los ministros, la mayoría de los tecnócratas $(54,5 \%)$ tienen poca trayectoria política al ser sólo militantes. Claramente el perfil de los subsecretarios de la Concertación es profesional con poca trayectoria política y con un carácter minoritariamente tecnocrático.

Para tener una visión más dinámica del rol de los tecnócratas en el proceso de toma de decisiones es que analizamos la presencia de éstos en los diferentes gabinetes que tuvo la Concertación entre 1990 y marzo de 2010. 


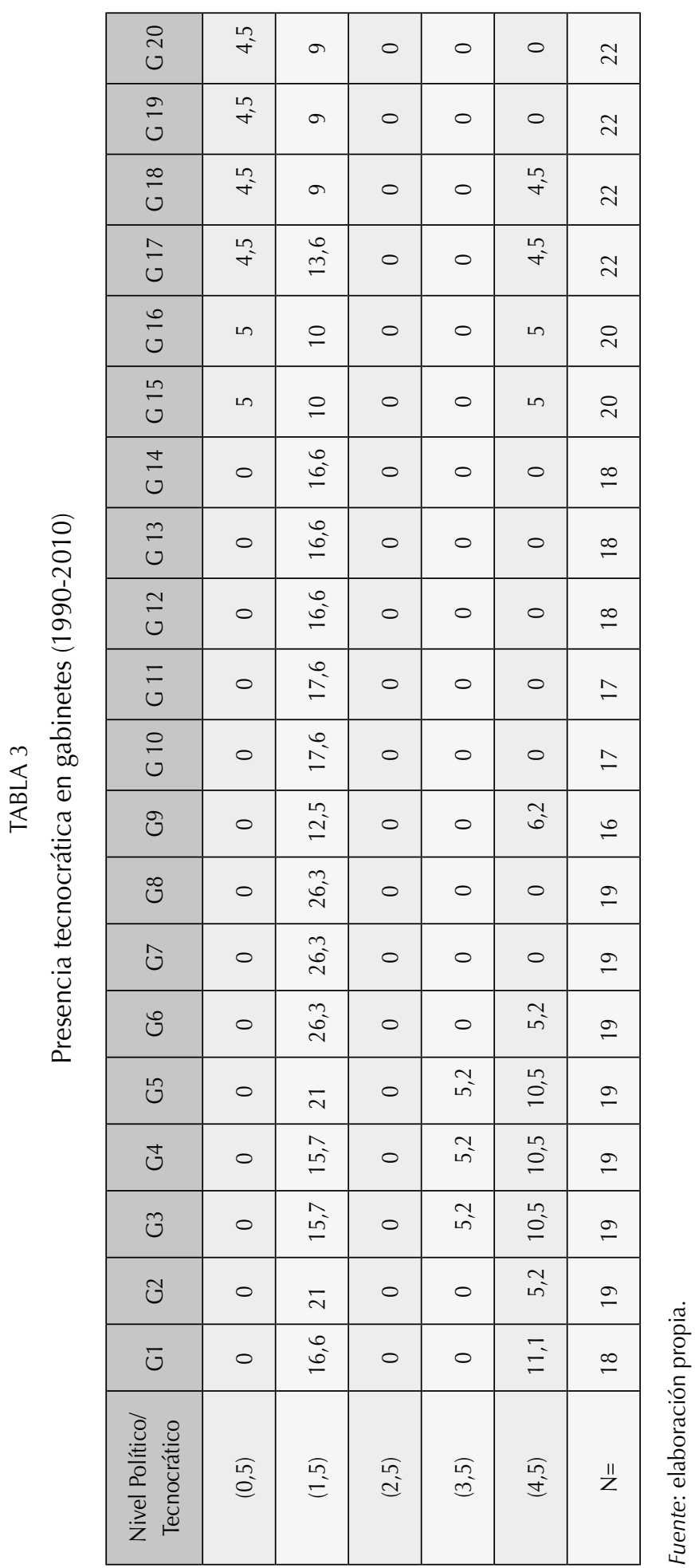


En el Tabla 3 se contabiliza la presencia de tecnócratas en los cuatro gobiernos de la Concertación a partir de los diferentes gabinetes que han tenido sus cuatro gobiernos.

Si observamos la Tabla 3 podemos concluir que, en general, los tecnócratas no superan un cuarto del total de ministros de los 20 gabinetes que la Concertación ha tenido desde el 11 de marzo de 1990. Ahora, como es sabido y reconocido por la literatura sobre gabinetes en sistemas parlamentarios (Laver y Hunt, 1992), no todos los ministerios son iguales en cuanto a importancia para los partidos miembros de la coalición y del peso de las políticas públicas. En ese sentido, los tecnócratas han dominado uno de los ministerios más importantes del gabinete tanto en sistemas parlamentarios como presidenciales, el Ministerio de Hacienda. En los cuatro gobiernos de la Concertación, los ministros de Hacienda son tecnócratas. De los 5 ministros de Hacienda que ha tenido esta coalición, sólo uno ha sido independiente (el Ministro de Hacienda de la administración Bachelet, Andrés Velasco), es decir, la mayoría es tecnócrata, pero tiene un vínculo partidario. Además, a excepción del Ministro Velasco, el resto de los ministros de Hacienda han pertenecido al partido del Presidente de la República. Respecto a los ministros de Economía, de los 10 ministros desde 1990, la mitad cumple con el perfil de tecnócrata.

\section{CONCLUSIONES}

Este artículo tuvo como objetivo poder desarrollar una metodología de medición del fenómeno tecnocrático en los niveles superiores de la administración del gobierno para poder contribuir a responder la pregunta cuál es la relación entre democracia y tecnocracia. Es así que a partir de esta medición podemos concluir una serie de ideas que nos permitirán seguir trabajando en la investigación de cómo se gobierna en el Chile contemporáneo.

Primero, se confirma para el caso chileno lo argumentado en cuanto a que la presencia tecnocrática está mediada por la política, en la medida que la gran mayoría de los tecnócratas pertenecen a algún partido político.

Segundo, y desde el punto de vista de la cuantificación solamente, la presencia de los tecnócratas no es numerosa como podría preverse en un Estado y en una democracia que la literatura ha calificado con una fuerte influencia tecnócrata. Se confirma la presencia en Hacienda de tecnócratas, pero en el resto del gabinete responde más a decisiones particulares del Presidente más que a un cierto perfil del cargo.

Tercero, la evidencia muestra que existe claramente una diferencia en la presencia de tecnócratas en el gabinete respecto de las subsecretarías. La notoria diferencia en la presencia de tecnócratas en el primero permite especular acerca de la causa de este patrón en la presencia de tecnócratas. Una primera se podría deber al nivel en que los tecnócratas buscan influir en el gobierno, lo cual a su vez se relaciona con las propias funciones de ministros y subsecretarios en el caso de un gobierno presidencial.

Cuarto, y para terminar, el análisis de los datos mostrados en este trabajo permite concluir que desde la perspectiva de la coalición de gobierno, sus líderes han combinado no sólo 
el expertise técnico propuesto por los tecnócratas, sino también la capacidad política para manejar un gobierno de coalición. En otras palabras, los partidos han dado espacio a los tecnócratas, pero además han mantenido gran cantidad de espacios de poder dentro del gobierno, lo cual ha permitido administrar los recursos del Estado con criterios mixtos que le permiten satisfacer las diferentes clientelas.

Es precisamente la relación entre los partidos y el Estado la que se tensiona con los cambios y modernizaciones en gestión del Estado de los últimos años. Quedan muchas preguntas abiertas para seguir investigando las complejidades que implica gobernar en el mundo de hoy.

\section{BIBLIOGRAFÍA}

Ai Camp, Roderic (1983): Mexico's leaders: education and recruitment, The University of Arizona Press, Tucson, Arizona.

(1985): "The Political Technocrat in Mexico and the Survival of Political System", Latin American Research Review, 20, pp. 97-117.

(1995): Political Recruitment across two centuries. Mexico, 1884-1991, University of Texas, Texas, EE.UU.

(1998): "Technocracy a la Mexicana: Antecedent to Democracy?", en Miguel Ángel Centeno y Patricio Silva (eds.): The Politics of Expertise in Latin America, St. Martin's Press, New York, pp. 177-195.

(2002): Mexico's Mandarins. Crafting a Power Elite for the twenty-first century, University of California Press, Berkeley, CA.

Akin, William (1977): "Technocracy and the American Dream. The Technocratic Movement, 19001941", University of California Press, Berkeley, CA.

Centeno, Miguel Ángel (1994): Democracy within Reason. Technocratic Revolution in Mexico.

(1997): "La política del conocimiento: Hayek y la tecnocracia", Pensamiento Iberoamericano, № 30, pp. 87-108.

Centeno, Miguel Ángel y Patricio Silva (1998): The Politics of Expertise in Latin America, St. Martin's Press, New York.

Collier, Simon (1979): The New Authoritarianism in Latin America, Princeton University Press, Princeton, NJ.

Conaghan, Catherine (1992): "Capitalists, technocrats and politicians: economic Policy making and democracy in the Central Andes", en Mainwaring et al. (eds.): Issues in Democratic Consolidation, Notre Dame University Press, Notre Dame, IN.

(1998): Stars of the Crisis: The Ascent of Economists in Peruvian Public Life, en Miguel Ángel Centeno y Patricio Silva (eds.): The Politics of Expertise in Latin America, St. Martin's Press, New York, pp. 142-164.

Corrales, Javier (2003): "Market Reforms", en Domínguez y Shiffer (eds.): Constructing Democratic Governance in Latin America, John Hopkins University Press, Baltimore.

Domínguez, Jorge (ed.) (1997): Technopols. Freeing Politics and Markets in Latin America in the 1990's, The Pennsylvania State University Press, Pennsylvania. 
Fischer, Frank (1990): The Politics of Expertise, Sage Publications, Newbury Park, CA.

Haggard, Stephan y Steven Webb (eds.) (1994): Voting for Reform; Democracy, Political Liberalization and Economic Adjustment, Oxford University Press, Washington DC.

Haggard, Stephan y Robert Kaufman (1995): The Political Economy of Democratic Transitions, Princeton University Press, Princeton, NJ.

Huneeus, Carlos (1998a): "Technocrats and Politicians in the Democratic Politics of Argentina (19831995)", en Miguel Ángel Centeno y Patricio Silva (eds.): The Politics of Expertise in Latin America, St. Martin's Press, New York.

(1998b): "Tecnócratas y Políticos en un Régimen Autoritario. Los ODEPLAN Boys y los Gremialistas en el Chile de Pinochet", Revista de Ciencia Política, Vol. XIX, pp. 125-158.

Laver, Michael y W. Ben Hunt (1992): Policy and Party Competition, Routledge, New York.

Lindau, Juan (1996): “Technocrats and Mexico's Political Elite”, Political Science Quarterly, Vol. 111, $\mathrm{N}^{\circ}$ 2, pp. 295-322.

Loureiro, María Rita (1997): "Los economistas como élites gobernantes. La dirección del Plan Real", Pensamiento Iberoamericano, 30, pp. 245-268.

Madrid, Raúl (2003): Retiring the State. The Politics of Pension Privatization in Latin America and Beyond, Stanford University Press, Stanford, CA.

Mauceri, Philip (1997): "Return of the Caudillo: Autocratic Democracy in Peru", Third World Quarterly, Vol. 18, No 5, pp. 899-911.

Meynaud, Jean (1968): Technocracy, Free Press, New York.

Montecinos, Verónica (1993): "Democrats and technocrats: professional economists and regime transitions in Latin America", Canadian Journal of Development Studies 1, pp. 7-22.

(1997): "El Valor Simbólico de los Economistas en la Democratización de la Política Chilena", Nueva Sociedad, № 152, pp. 108-126.

(1998a): Economists, Politics and the State, Chile 1958-1994, CEDLA, Amsterdam, Netherlands.

(1998b): "Economists in Party Politics: Chilean Democracy in the Era of the Markets", en Miguel Ángel Centeno y Patricio Silva (eds.): The Politics of Expertise in Latin America, St. Martin's Press, New York.

Montecinos, Verónica y John Markoff (1993): "Democrats and Technocrats: professional economists and Regimen Transitions in Latin America", Canadian Journal of Development Studies, № 1, pp. 7-22.

Moreno, Marco (2007): "La tensión entre decisiones técnicas y políticas", Diálogos de Políticas Públicas, FLACSO, Santiago, Chile, pp. 23-31.

Pastor, Manuel y Carol Wise (1992): “Peruvian Mexico: Economic Policy in the 1980's: From Orthodoxy to Heterodoxy and Back", Latin American Research Review, 27 (2), pp. 83-117.

Picon, Antoine (2007): "French Engineers and Social Thought, 18-20 Centuries: An Archeology of Technocratic Ideals", History and Technology, Vol. 23, № 3, pp. 197-208.

Rehren, Alfredo (1998): “La Organización de la Presidencia y el Proceso Político Chileno", Revista de Ciencia Política, Vol. XIX, pp. 89-124. 
Ross Schneider (1997): "Las bases materiales de la tecnocracia: la confianza de los inversores y el neoliberalismo en América Latina", Pensamiento Iberoamericano, 30, pp. 109-132.

(2004): Business politics and the state in Twentieth-Century Latin America, Cambridge University Press, Cambridge, New York.

Silva, Eduardo (1993): "Capitalist Coalitions, the State, and Neoliberal Economic Restructuring: Chile, 1973-1988", World Politics, Vol. 45, № 4, pp. 526-559.

Silva, Patricio (1991): "Technocrats and Politics in Chile: From the Chicago Boys to CIEPLAN Monks", Journal of Latin American Studies, vol. 23, № 2, pp. 385-410.

(1994): "State, Public Technocracy and Politics in Chile, 1927-1941", Bulletin of Latin American Research, vol. 13, № 3, pp. 281-297.

(1996): "Studying Technocracy in Chile, What Can be Learned from the Mexican Case?", European Review of Latin American and Caribbean Studies, 61, pp. 39-64.

(2001): "Towards Technocratic Mass Politics in Chile? The 1999-2000 Elections and the Lavín Phenomenon", European Review of Latin American and Caribbean Studies, 70, pp. 25-39.

(2006): "Los Tecnócratas y la Política en Chile. Pasado y Presente", Revista de Ciencia Política, Vol. XXVI, No 2, Instituto Ciencia Política UC, pp. 175-190.

(2009): In the Name of Reason. Technocrats and Politics in Chile, The Pennsylvania State University Press, University Park, Penn.

Teichman, Judith (1997): "Mexico and Argentina: Economic Reform and Technocratic Decision Making", Studies in Comparative International Development, 32, pp. 31-55.

(2001): The Politics of Freeing Markets in Latin America, The University of North Carolina Press, North Carolina.

Whitehead, John (1997): “La política del conocimiento especializado en América Latina: Antecedentes y tendencias contemporáneas", Pensamiento Iberoamericano, №30, pp. 37-54. 
